RISUS - Journal on Innovation and Sustainability ISSN 2179-3565
RISUS - Journal on Innovation and Sustainability volume 8, número 3 - 2017 ISSN: 2179-3565

Editor Científico: Arnoldo José de Hoyos Guevara Editora Assistente: Lívia Lopes Aguiar

Avaliação: Melhores práticas editoriais da ANPAD

\title{
SIX STEPS IMPLEMENTATION FRAMEWORK FOR CORPORATE SUSTAINABILITY PERFORMANCE MANAGEMENT
}

\author{
Seis passos na Implementação de um framework para uma Gestão Corporativa Sustentável
}

\author{
Muhammad Tasleem ${ }^{1}$, Nawar Khan ${ }^{1}$, Syed Tasweer Hussain Shah ${ }^{1}$, \\ Muhammad Saleem ${ }^{1}$, Asim Nisar ${ }^{2}$ \\ 1National University of Sciences and Technology, Islamabad, Pakistan \\ 2 Centres of Excellence in Science and Applied Technologies, Islamabad, Pakistan \\ E-mail:m.tasleem@ceme.nust.edu.pk,nwr_khan@yahoo.com, \\ tasweer2001@yahoo.com,ranasaleem096@yahoo.com, aasim_n@yahoo.com
}

\begin{abstract}
Managing sustainability practices holistically within firms is challenging and requires a sound and effective management framework that integrates all associated practices and performance dimensions to act for excellence. Corporate management is keen to adopt roadmap or a framework that can be useful in the identification, management and measurement of the drivers and can lead to desired outcomes relating to sustainable performance. This paper develops and presents a six-steps implementation framework for corporate sustainability performance and related practices keeping in account multifaceted managerial dimensions. These six steps include; identifying stakeholder's requirements, establishing enterprise vision and sustainability goals, adopting strategies, systems and standardization, aligning technologies, core capabilities and culture, excelling sustainability performance, and progressing sustainable improvement with review and feedback. It also projects the perspective, theme and action items with regard to its effective. Keywords: Sustainability, corporate sustainability performance, excellence, technologies
\end{abstract}

Resumo: Gerenciar práticas de sustentabilidade de forma holística dentro das empresas é um desafio que requer uma estrutura de gerenciamento sólida e eficaz que integre todas as práticas associadas e as dimensões de desempenho para alcançar excelência. $\mathrm{O}$ gerenciamento corporativo precisa estar aberto para adotar o roteiro o framework que pode ser útil na identificação, gerenciamento e medição dos drivers que podem levar a resultados desejados relacionados ao desempenho sustentável. Este artigo desenvolve e apresenta um quadro de implementação de seis etapas para o desempenho de sustentabilidade corporativa e práticas relacionadas mantendo em conta dimensões gerenciais multifacetadas. Estes seis passos incluem; identificar os requisitos das partes interessadas, estabelecer a visão corporativa e os objetivos de sustentabilidade, adotar estratégias, sistemas e padronização, alinhar tecnologias, recursos essenciais e cultura, alcançar excelência no desempenho de sustentabilidade e avançar progressivamente na melhoria sustentável com revisão e feedback. Ele também projeta a perspectiva, tema e os itens de ação para se tornar efetivo o processo.

Palavras chave: Sustentabilidade, desempenho de sustentabilidade corporativa, excelência, tecnologias 


\section{INTRODUCTION}

Sustainability is an ethical dilemma based on natural values and principles. Its significance in business world is now very much recognized (Laine, 2010). Managing sustainability holistically in corporations or firms is challenging and requires a sound management framework that integrates all associated performance dimensions (Johnson, 2007; Sabhatu, 2008). According to Epstein (2008), management is keener to understand how companies can improve sustainability performance, and more specifically, how they can identify, manage and measure the drivers of sustainability that can lead to improve corporate's system, operations and results. Though various initiatives and implementation strategies have been introduced, however, it remains a challenge for the management to ensure that these initiatives can be successfully intact in their existing system. Therefore practical implications and barriers for the implementation of these strategies require genuine guidelines and methodologies. This paper overviews the concept of corporate sustainability and related implementation guidelines, and presents and discusses in detail a six-steps implementation framework for corporate sustainability performance keeping in account multifaceted managerial dimensions. These six steps include; identifying stakeholder's requirements, establishing enterprise vision and sustainability goals, adopting strategies, systems and standardization, aligning technologies, core capabilities and culture, excelling sustainability performance, and progressing sustainable improvement with review and feedback. The discussion also encompasses the perspective, theme and action items with regard to its effective implementation.

\section{THEORATICAL REVIEW}

\section{Corporate Sustainability}

Dyllick and Hockerts (2002) define corporate sustainability as "meeting the needs of a firm's direct and indirect stakeholders without compromising its ability to meet the needs for future stakeholders as well". The Dow Jones Sustainability Index (DJSI) defines the term corporate sustainability as: "a business approach that creates long-term shareholder value by embracing opportunities and managing risks deriving from economic, environmental and social developments ... corporate sustainability leaders achieve long-term shareholder value by gearing their strategies and management to harness the market's potential for sustainability products and services while at the same time successfully reducing and avoiding sustainability costs and risks". Corporate sustainability is a way to eliminate conflicts of goals among economic, social and environmental issues. Rather it creates situation of goal congruence while establishing long term objectives related to the growth of economy, conservation of the biophysical environment and responsible actions to benefit society. Bybalancing the three dimensions of sustainability, awin-win situation can be created by changing the goal conflicts to goal congruence (Steimle \& Zink, 2006). Authors have a view that corporate sustainability performance (CSP) is a way to competitive advantage. They define sustainability as 'the ability of an organization to adapt to change in the business environment to capture contemporary best practice methods and to achieve and maintain superior competitive performance" (Zairi \& Liburd, 2001). Nidumolu et al. (2009) asserted that only organizations that make sustainability a goal will gain competitive advantage in the future. 


\section{Implementing Sustainability}

According to James and Lathi (2004), there are guidelines initiated for companies by TNS for developing, managing and enhancing sustainability education, strategies as well as initiatives. This methodology comprises 4 phases, namely, creating and supporting:

1. Understanding and awareness

2. Baseline assessment

3. Vision and strategic plan

4. Effective implementation in steps

Grayson et al. (2008) are of the opinion that shareholder and social aspects hold added value in business. They developed S2AVE (Shareholder and Social Added Value with Environment Restoration), which is an approach towards sustainability practices. S2AVE emphasizes that companies can effectively and successfully cater to all three TBL elements, at the same time. The ten steps of S2AVE are:

- Setting vision for sustainability innovation.

- Considering sustainability an imperative part of strategy

- Embed sustainability in all business aspects

- Stressing actions instead of words

- Implement a committee for managing sustainability

- Incorporate defined rules

- Identify and involve stakeholders for support

- Enhance people power

- Integration of key networks and alignment of business systems

- Proper documentation and reporting of sustainability performance

McElroy and Engelen (2012) presented Corporate Sustainability Management (CSM) Cycle, which is implemented in six steps:

1. CSM function initiation

2. Identifying stakeholders

3. Establishing performance standards

4. Gauging performance

5. Planning for strategies and interventions

6. Implementation of planned strategies and interventions

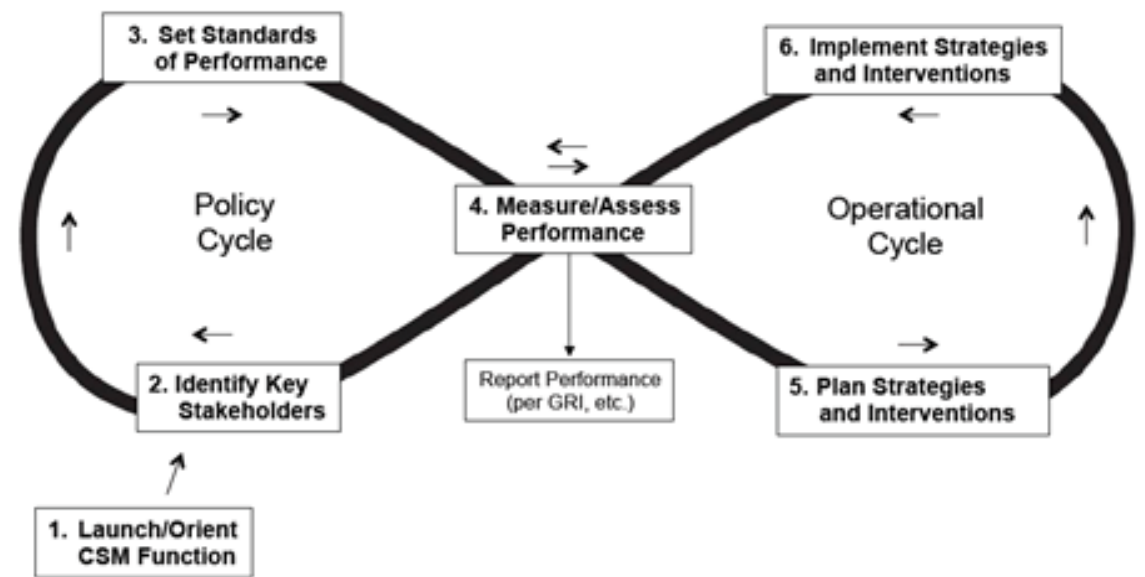

Figure 1: The CSM Cycle

Source: McElroy \& Engelen (2012) 


\section{CORPORATE SUSTAINABILITY PERFORMANCE MANAGEMENT FRAMEWORK}

Figure 2 places a roadmap in form of framework outline that can be adopted for achieving the desired outcomes relating to sustainability performance and excellence. The framework is a general roadmap, which depicts an implementation strategy in six major steps as depicted below;

1. Identifying stakeholders and their requirements

2. Establishing mission, sustainability goals and indicators

3. Adopting strategies, systems and standardization

4. Aligning technologies, capabilities and culture

5. Excelling incorporate sustainability performance

6. Feedback and improvement: reporting, reviewing and reviving

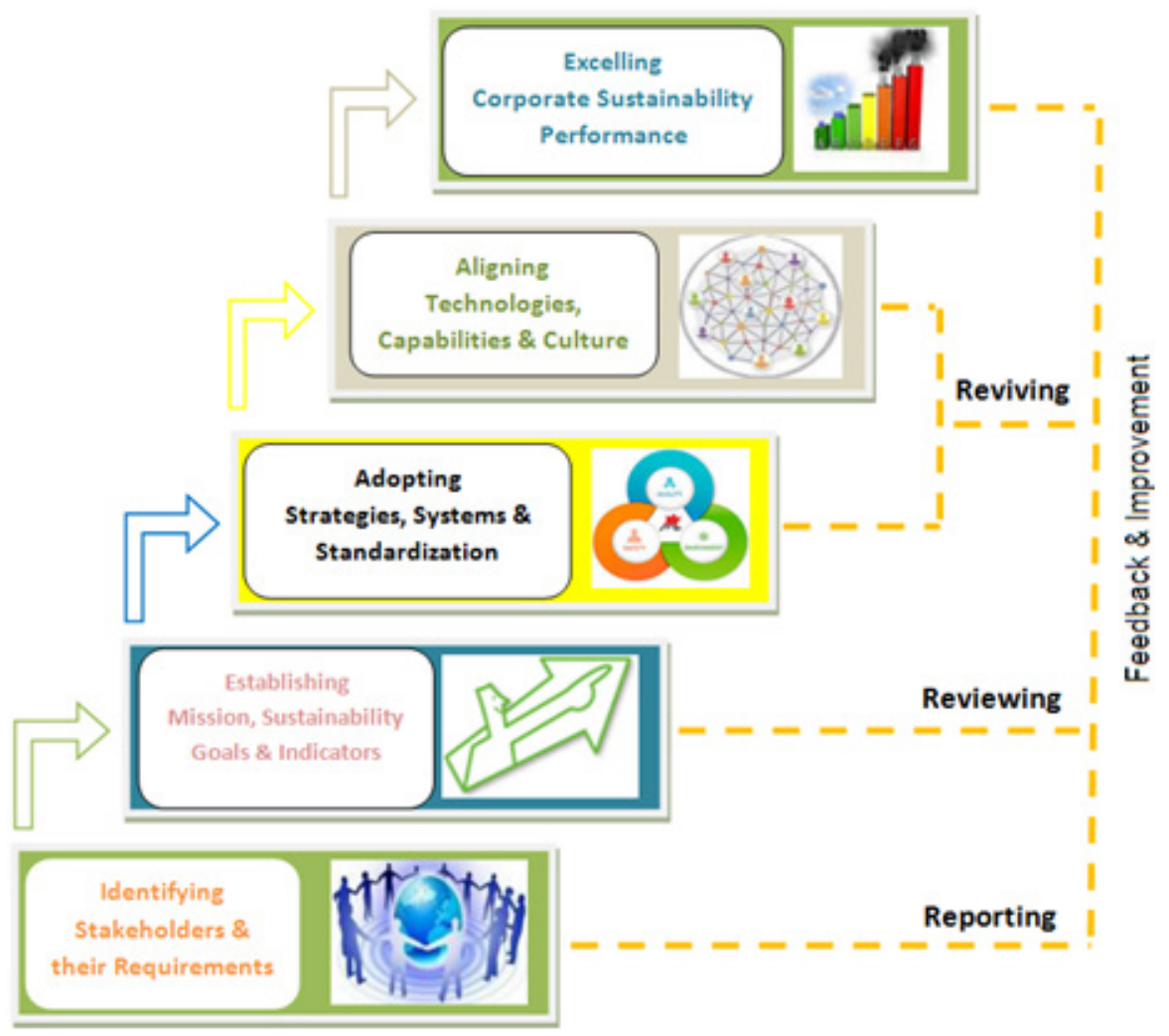

Figure 2: Corporate Sustainability Performance Management Framework

Each step further outlines range of major concepts or fields. The perspective and action items of each step are summarized in Table 1, while brief detail of each step is presented below. 


\section{DISCUSSION}

\section{Step 1 - Identifying Stakeholders \& their Requirements}

Sustainability has become an important and acceptable phenomenon by organizations of each size. Every organization interacts with certain stakeholders inside and outside its set up. For larger firms the number and types of stakeholders is much bigger than smaller ones. For the successful implementation of sustainability initiatives in firms it is most vital to understand who are stakeholders, what are their requirements, and to what extent they have or can influence the operational activities and outcomes. These stakeholders have impact in shaping the firm's policies, structures, decisions and operations.

According to Johansson (2007), there are various kinds of stakeholders in perspective to corporate sustainability including customers, employees, suppliers, regulatory agencies, investors, shareholders, public and community. Each stakeholder has its own interests and needs. The concept of corporate sustainability ascertains to bring harmony between all the shared and opposing interests of key stakeholders in order to carry long lasting business results and outcomes. Thus it becomes important to identify key stakeholders and to prioritize their needs and requirements.

The stakeholder theory discusses aspects related to the measuring organizational performance keeping in mind the interests of all stakeholders in the activities and functionalities of the firm. According to this theory, performance measurement must be done with reference to the stakeholders. Stakeholders may include communities, corresponding governments, and stakeholders that may have direct transactional relationship.

Funk (2003) states that a sustainable firm is the one "whose characteristics and actions are designed to lead to a 'desirable future state' for all stakeholders". It has also been asserted continuously by the United Nations (UN) to attain the objectives that demand business leaders to advance from short-term shareholder value to longer-term aspects of a wider range of stakeholders. Latham (2012) discusses that sustainable development supports value creation for the present stakeholders as well as the future generations of stakeholders.

Stakeholder analysis can be considered as a management technique used to highlight key stakeholders that may influence the organization or even project performance. There needs to be a balance amidst economic targets, social and environmental values, stakeholder needs. Stakeholder analysis can be most effective by:

- Highlighting and identifying influential stakeholders

- Assessing needs of stakeholders thoroughly

- Asserting better understanding of requirements

- Promoting unhindered communication between different groups

- Acquiring support and dedicated commitment from stakeholders

- Enhancing stakeholder's satisfaction through their involvement 


\section{Step 2 - Establishing Mission, Sustainability Goals and Indicators}

A mission identifies the purpose behind the unified effort to achieve goals. A mission statement of an organization defines the nature of business and the value to be generated for the stakeholders by the organization. The success of an organization can be determined by the commitment to mission. Business organizations must consider the contribution to the growth of sustainable development as a part of mission. By managing organizations and related operations based on sustainability principles and practices, a larger and more upright scope of mission can be defined.

Goals can be considered as the results and targets that organizations and other entities establish to achieve. Goals help map out the ways for teams and employees by which they can put in efforts. Goals may be long term or short term, where short terms goals are actually a part of the long term goals. Objectives and targets are also components of larger goal, and hold different meanings. The goals of businesses and organizations may be established to cater to multiple areas. These areas may include increase in revenue, more profitability, higher customer satisfaction, business expansion, service performance, etc. This may also include reduction of operational costs, product complaints and defects, etc. To attain direction for sustainability, the organizational approach must be also towards environmental and social performance in addition to generating revenue. It should include establishing goals to attain betterment of the society, environment, the society, stakeholder value and employee welfare, as well as business enhancement. This can be a great source of motivation and can promote competitiveness within the teams and the workforce.

In order for goals to be effectively and efficiently examined, they need to be set in measurable form. For this purpose, indicators and metrics can be incorporated to display targets and performance in measurable terms. With the help of these indicators, an organization can view performance levels on a timely basis against these goals or targets. Indicators can be in the form of percentages, ratios or just numbers, and may be quantitative or qualitative. The most efficient way to get results is to combine both. Staniškis and Arbačiauskas (2009) suggest four types of quantifiable indicators: 1. absolute indicators, 2. relative indicators, 3. aggregate indicators and 4. indexed indicators. In aggregate and indexed indicators, data is integrated either in various categories or as level of performance portrayed as a number. These indicators are useful during the overall assessment of the performance of a business, although they may lack in depth information, which proves as a limitation in their practical use with reference to identifying opportunities for optimizing performance. For that purpose, it is better to use of absolute and relative indicators. Decision making is one area in which relative indicators can be useful since they allow to examine the changes of particular values (e.g. pollution) corresponding to a common denominator (e.g. raw material or production unit). On the other hand, absolute and relative indicators may be portrayed in natural units (tons, liters etc.) as well as monetary units.

Identified indicators can help evaluate improvement in sustainability performance in all three dimensions. An array of sustainability indicators and goals has been specified by international sustainability reporting systems. Business organizations can adopt guidelines and gain benefits from these reporting standards and systems. Sustainability indicators that are concerned with social as well as environmental issues must relate to external and internal stakeholder needs throughout the product life cycle (Funk, 2003; Seuring et al., 2003).

Another way to substantiate strategic planning is through SWOT analysis and scanning environmental factors and risks that may affect the organization directly or indirectly. The Hoshin Kanri technique can be implemented in the strategic management process. 


\section{Step 3 - Adopting Strategies, Systems and Standardization}

A strategy can he defined as a high level action plan or methodology designed to acquire an aim, a goal or results. It gives a picture of the methods needed to bring about desired effects. Strategic management involves planning, monitoring and assessing coordination to achieve organizational aims and goals using resources within the organization. Quality is proved to be a strategic entity in business operations and it should be in sync with all other business strategies. Quality is termed as the management action at the corporate level. According to Gill (2009), TQM is a strategy for continuous change and can also be seen as a strategic management model. Atkinson and Naden (1989) define TQM as a strategy that can bring about a change in organizational beliefs, culture, corporate values and promote enthusiasm and happiness among the workforce. Some examples of strategic quality or TQM models may encompass national and regional quality awards, and BE frameworks.

TQM, CSR, and benchmarking are the various forms of strategies that can be implemented in a management system, whereby a system comprises a network of interrelated elements that results in a complex or unitary whole. The system management keeps holds various entities of the corresponding system in coordination with each other in an efficient manner in order to achieve the planned mission. Within a business enterprise, various systems can function, such as performance management system, accounting system, information system, quality management system, and accounting system, etc. For more efficiency, the management system standards adopted by companies whether international or national, can be merged as an Integrated Management System (IMS). Pojasek (2007) has laid emphasis on integration of business sustainability framework with management system standards.

Standards are termed as the required norms, specifications or guidelines that may be needed to establish a system within an entity. Standards, for any organization, portray the characteristics of the system for effective functionalities. Some of the known standards, such as ISO 9001, ISO 14001 and OHSAS 18001 standards, provide guidelines for improving management systems for quality, environment and safety, respectively. Organizations may adopt an integrated approach or implementation of series of standards in stages. The ISO 9001 QMS standard can be implemented foremost followed by other standards as it is the mother standard. To achieve improved results, Enablon, a management consultancy firm, has introduced QEHS Management software to aim for efficient integration of standards within the systems

\section{Step 4 - Aligning Technologies, Capabilities and Culture}

Alignment and efficient use of resources is imperative to implement standards, strategies and systems. The strength of any organization comprises it's technology, capability as well as core competencies. These hold the basis for business competitiveness and growth. It is important to acquire and manage technologies that can help attain solutions to high level customer requirements in order to boost process efficiency. According to Tsai et. al. (2013), technology helps generate business value and influences the performance of the organization. It is also significant for reduction of the environmental deterioration. 
Green Technology has been seen as one of the latest fields, which aim at using evolving groups of materials and methods in order to produce environment-friendly products with efficient utilization of energy resources. Environmental technologies encompass various entities including methods, techniques, product designing, devices, production equipments along with delivery mechanisms that focus on conserving energy and natural resources and that cater to environmental protection. Environmental technologies comprise of hardware (equipment used for pollution control, ecological measurement, etc.) as well as managerial (designing products, process methodology, monitoring systems, etc.). According to findings by Klassen and Whybark (1999), manufacturing performance can be greatly improved through environmental technology, especially using technologies related to pollution prevention.

Organizational capability can be termed as the capability of the organization to manage all its resources, in the most efficient and effective way, including its human resource, for acquiring competitive advantage in the market. Organizational success with sustainable performance can be attained through effective deployment of organizational capabilities. Core capabilities of an organization, which are technology and management, if integrated efficiently, can not only result in sustainable performance but also are difficult to compete with by other organizations (Chumaidiyah, 2011). Therefore, it is imperative that an organization invest in developing core capabilities that can play a role in maintaining its sustainability along with retaining competitive advantage (Tsai et al., 2013). It is very important that the management in an organization must work towards developing a plan that aims at improving overall capabilities of the organization. These abilities may include human resources, technological, supply chain, financial, operational as well as the production capability. Organizations that work on management of resources efficiently can easily attain their goals, mission, strategy and plan of action.

The culture of any organization plays a great role in its potential to achieve success. Therefore, the organizational culture should be established such that it helps provide maximum support to organizational progress. According to Linnenlueke and Griffiths (2010), there is seen a close connection between corporate sustainability and the organizational culture. Culture can be seen as a complex whole that holds a variety of interrelated entities including beliefs, law, customs and morals and art. The culture of a firm can define its success or failure, with reference to the system or general enterprise goals. Without the positive contribution and involvement of the workforce, the success of the organization cannot be based on only equipment and machinery. The implementation of TQM can help promote a culture of continual betterment and employee involvement, there by supporting its overall resource management for working to achieve the firm's goals. TQM also involves stakeholders, which is another reason why it should be implemented to obtain sustainability results.

\section{Step 5 - Excelling Corporate Sustainability Performance}

Implementation of sustainability practices is more successful when there is more clarity of stated mission, goals and strategies, and there is harmony among the system, technologies, capabilities and culture. This phase requires intelligent deployment of strategies, implementation of green technologies, application of process controls and efficiency, management of pollution control, waste management and constant monitoring of sustainability, and other performance parameters. 
The Sustainability Excellence Management System (SEMS), launched by Goldcorp Inc. provides a framework and set of procedures for implementing and maintaining corporate level sustainability performance. It assists to develop a platform for delivering and measuring sustainability impact. SAP Sustainability Performance Management Software has been introduced by SAP, which can assist corporate management in measuring impact and driving sustainability initiatives and goals. The software is helpful in aligning sustainability KPIs with goals, improving data collection and reporting accuracy, tracking sustainability performance. However, implications for the cost and integration of such softwares with other established technologies and systems must be evaluated before implementing in the organization.

In this stage, it is important to ensure that the strategies are deployed efficiently, green technology is implemented, process controls are applied efficiency, effective pollution control and waste management along with consistent monitoring of sustainability, and other performance parameters. Sustainability practices may be better implemented when the stated mission, goals and strategies are clear and the culture, capabilities, system and technology are well coordinated.

The Sustainability Excellence Management System (SEMS) was initiated by Goldcorp, Inc. It provides a framework to implement and maintain sustainability performance at the organizational level as well as developing a platform to measure and deliver sustainability impact. SAP Sustainability Performance Management Software, introduced by SAP, can help an organization guage impact and establish the sustainability initiatives and goals. It can also be used to help improve data collection, accuracy in reporting, sync sustainability KPIs with goals and keep track of sustainability performance. In any case, before adopting such a software, it is important to assess the cost and whether it integrates with other established technologies and systems.

\section{Step 6 - Feedback and Improvement: Reporting, Reviewing and Reviving}

There are different ways of reporting in organizations. An organization can carry out reporting in multiple ways, each having its own implications. The management of a firm measures progress and carries out it's decision making process by utilizing data in each functional area. Keeping stakeholders informed about the organization's performance is a key requirement to reinforce support from stakeholders. Furthermore, the root causes can be identified and improvement can be done in a firm by using correct information or data.

One of the most important elements of the process to attain more business and sustainability development is performance reporting. According to Sebhatu (2008), reporting can depict a company's commitment and ability to communicate with external stakeholders. A sustainability report documents a firm's operational activities and is published by the firm itself with reference to its economic, environmental and social influence. In an organization, there can be a number of sustainability reporting initiatives e.g. GRI, the DJSI, EPI and SAM criteria 
Table 1

Perspective, Theme and Action Items of the Framework Steps

\begin{tabular}{|c|c|c|c|}
\hline Steps & Perspective & Theme & Action Items \\
\hline Step-1 & 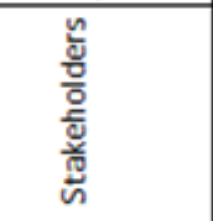 & $\begin{array}{c}\text { Identifying } \\
\text { Stakeholders \& } \\
\text { their } \\
\text { Requirements }\end{array}$ & $\begin{array}{l}\text { - Key stakeholders (Government, regulatory bodies, } \\
\text { social \& political groups, community, customers, } \\
\text { users, suppliers, etc.) } \\
\text { - Stakeholder analysis } \\
\text { - Needs, wants and requirements of stakeholders }\end{array}$ \\
\hline Step-2 & 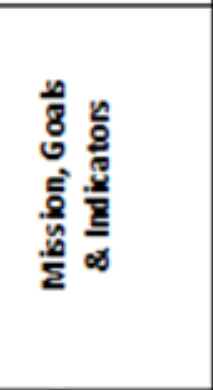 & $\begin{array}{l}\text { Establishing } \\
\text { Mission, } \\
\text { Sustainability } \\
\text { Goals \& } \\
\text { Indicators }\end{array}$ & $\begin{array}{l}\text { - Organizational vision admission } \\
\text { - SWOT analysis } \\
\text { - Environmental scanning } \\
\text { - Risk analysis and management } \\
\text { - Strategic planning } \\
\text { - Hoshin Kanri } \\
\text { - Goals, objectives, targets } \\
\text { - Measurable indicators } \\
\text { - Action plans }\end{array}$ \\
\hline Step-3 & 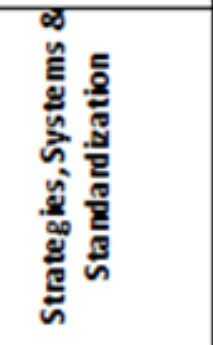 & $\begin{array}{c}\text { Adopting } \\
\text { Strategies, } \\
\text { Systems \& } \\
\text { Standardization }\end{array}$ & $\begin{array}{l}\text { - Strategic (quality) management } \\
\text { - TQM } \\
\text { - Benchmarking } \\
\text { - CSR } \\
\text { - MSSs } \\
\text { - IMS } \\
\text { - Quality Awards } \\
\text { - Sustainability Initiatives and Reporting }\end{array}$ \\
\hline Step-4 & 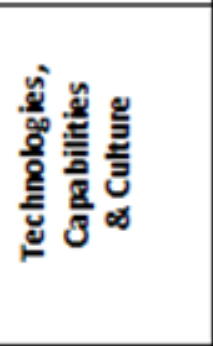 & $\begin{array}{c}\text { Aligning } \\
\text { Technologies, } \\
\text { Capabilities and } \\
\text { Culture }\end{array}$ & $\begin{array}{l}\text { - Technology Management } \\
\text { - Innovation } \\
\text { - Resource mobilization } \\
\text { - Clean Technology } \\
\text { - Green supply chain management } \\
\text { - Green IT } \\
\text { - Workforce development } \\
\text { - Culture development \& refinement }\end{array}$ \\
\hline Step-5 & 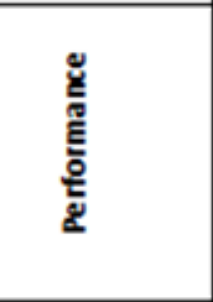 & $\begin{array}{c}\text { Excelling } \\
\text { Corporate } \\
\text { Sustainability } \\
\text { Performance }\end{array}$ & $\begin{array}{l}\text { - Deployment of strategies \& technologies } \\
\text { - Process control \& efficiency } \\
\text { - Pollution Prevention } \\
\text { - Waste management } \\
\text { - Performance measurement } \\
\text { - Monitoring } \\
\text { - Auditing }\end{array}$ \\
\hline Step-6 & 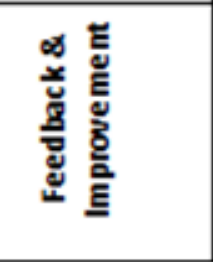 & $\begin{array}{l}\text { Feedback \& } \\
\text { Improvement: } \\
\text { Reporting, } \\
\text { Reviewing \& } \\
\text { Reviving }\end{array}$ & $\begin{array}{l}\text { - } \text { Feedback } \\
\text { - Reporting } \\
\text { - Review } \\
\text { - Revive } \\
\text { - Corrective \& Preventive Actions } \\
\text { - Improvement } \\
\end{array}$ \\
\hline
\end{tabular}

Source: Maletič et al., 2012 
Reviewing comprises the evaluation of the company's progress in terms of it's KPIs, planning and objectives. Reviews are done in the form of audit, report analyses, group discussions, and brain storming, etc. Formal reviews carried out by experts or management professionals can guide in identifying problem areas, gaps, improvement opportunities and desired realignment of goals and strategies.

Reporting and reviewing processes can guide in various functions e.g. modifying or realigning of system, organizational strategy, capabilities and cultural initiatives. Reviving can be termed as the process of renovating and re-modifying the organizational structure, functions, system as well as its culture. There may be a need to manage larger changes that may be handled with Business Process Reengineering (BPR) process, or smaller changes that can be catered to using standard preventive as well as corrective plan of action.

The above described six steps altogether can be initiated and carried forward simultaneously, that is why the steps shown in Figure 2 overlap each other to certain extent, however every higher step cannot be finished till the successful implementation of elements of prior step. Each step has a distinctive perspective, theme and certain action items which are, adapted from the work of Maletič et al. (2012), and highlighted in Table 1 as a management tool box. Though the list of action items is exhaustive but a few other relevant concepts of the field may also be included. Majorly the perspective and theme of each step is indispensable for recognition and develop rationale for way forward to corporate sustainability performance.

\section{CONCLUSIONS}

In pursuit to excel performance, particularly linked in sustainability terms, certainly there is an elementary need to develop a path that can show an effective way of implementation and achievement of desired results. This paper presents and elaborates a management framework of corporate sustainability performance for the effective implementation of sustainability matter in firms. The implementation has been suggested in six stages. As a first step, it is asserted that identification of stakeholders and their requirements is most important in driving corporate mission, goals and sustainability indicators and formulating action strategies. Further it is discussed that adoption of management system standards, development of culture and alignment of technologies and capabilities will be effective in attaining sustainability goals. A constant monitoring through reporting and review can help to re-align and improve sustainability performance.

Future research can be carried out to investigate any factors and barriers that can impede the successful implementation. Moreover empirical investigation of the framework can be determined by its implementation in different types of industries and organizations. 


\section{REFERENCES}

Atkinson, P. E., \& Naden, J. (1989). Total quality management: eight lessons to learn from Japan. Management Services, 33, 6-10.

Chumaidiyah, E. (2011). Theoretical Framework: The Influence of Core Technical Competence and Core Marketing Competence to Competitive Advantage. In Proceedings The 2nd International Conference on Industrial Engineering And Operations Management (IEOM). Kuala Lumpur, Malaysia.

Dyllick, T., \& Hockerts, K. (2002). Beyond the business case for corporate sustainability. Business strategy and the environment, 11(2), 130-141.

Epstein, M. J. (2008). Making Sustainability Work: Best practices in managing and measuring social and environmental impacts, Greenleaf, Sheffield.

Funk, K. (2003). Sustainability and performance. MIT Sloan Management Review, $44(2), 65$.

Gill, J. (2009). Quality follows quality: add quality to the business and quality will multiply the profits. The TQM Journal, 21(5), 530-539.

Grayson, D., Rodriguez, M. A., Lemon, M., Jin, Z., Slaughter, S., \& Tay, S. (2008). A new mindset for corporate sustainability. A white paper sponsored by BT and Cisco.

James, S., \& Lahti, T. (2004). The natural step for communities: how cities and towns can change to sustainable practices. New society publishers.

Johansson, P. (2007). Quality management and sustainability: exploring stakeholder orientation. MSc dissertation. Luleå University of Technology, Sweden.

Klassen, R. D., \& Whybark, D. C. (1999). The impact of environmental technologies on manufacturing performance. Academy of Management journal, 42(6), 599-615.

Laine, M. (2010). Towards sustaining the status quo: Business talk of sustainability in Finnish corporate disclosures 1987-2005. European Accounting Review, 19(2), 247-274.

Latham, J. R. (2012). Management System design for sustainable Excellence: framework, practices and considerations. Latham, JR (2012). Management system design for sustainable excellence: Framework, practices and considerations. Quality Management Journal, 19(2), 15.

Linnenluecke, M. K., \& Griffiths, A. (2010). Corporate sustainability and organizational culture. Journal of world business, 45(4), 357-366. 
Maletič, M., Maletič, D., \& Gomišček, B. (2012, May). An organizational sustainability performance measurement framework. In Recent researches in environment, energy systems and sustainability: proceedings of the 8th WSEAS International conference on Energy, Environment, Ecosystems and Sustainable development (EEESD'12), Faro, Portugal (pp. 220-225).

McElroy, M. W., \& Van Engelen, J. M. (2012). Corporate sustainability management: The art and science of managing non-financial performance. Routledge.

Nidumolu, R., Prahalad, C. K., \& Rangaswami, M. R. (2009). Why sustainability is now the key driver of innovation. Harvard business review 87(9), 56-64.

Pojasek, R. B., \& Hollist, J. T. (2011). Improving sustainability results with performance frameworks. Environmental Quality Management, 20(4), 81-96.

Sebhatu, S. P. (2008). Sustainability performance measurement for sustainable organizations: beyond compliance and reporting. In 11th QMOD Conference Quality Management and Organizational Development Attaining Sustainability From Organizational Excellence to SustainAble Excellence, Helsingborg; Sweden (No. 033). Linköping University Electronic Press.

Seuring, S. A., Koplin, J., Behrens, T., \& Schneidewind, U. (2003). Sustainability assessment in the German detergent industry: from stakeholder involvement to sustainability indicators. Sustainable Development, 11(4), 199-212.

Staniškis, J. K., \& Arbačiauskas, V. (2009). Sustainability performance indicators for industrial enterprise management. Environmental Research, Engineering and Management, 48(2), 42-50.

Steimle, U., \& Zink, K. J. (2006). Sustainable development and human factors. International Encyclopedia of Ergonomics and human Factors, 2258-2263.

Tsai, M., Tsai, M., \& Change, C. (2013). The direct and indirect factors on affecting organizational sustainability. Journal of Management and Sustainability, 3(4), 67-77.

Zairi, M., \& Liburd, I. M. (2001, April). TQM sustainability-a roadmap for creating competitive advantage. In Integrated Management, Proceeding of the 6 th International Conference on ISO 9000 and TQM (pp. 452-461). 